\title{
Improved Reproductive Health Equity Between the Poor and the Rich: An Analysis of Trends in 46 Low- and Middle-Income Countries
}

\author{
John Ross ${ }^{a}$
}

\begin{abstract}
In light of advocacy efforts to reach the poorest with better health services, an examination of recent history reveals that overall the poor-rich gap in contraceptive use is already narrowing substantially, and more so where family planning programs are stronger. For most of 18 other reproductive health indicators, the gap is also narrowing. However, contraceptive use gaps in many sub-Saharan African countries have not diminished, calling for strong family planning program efforts to improve equity.
\end{abstract}

\begin{abstract}
While several indicators for reproductive health have improved for entire populations, few analyses are available for trends over time in the gaps between the poor and the rich. This paper tracks improvements in the equitable distribution of reproductive health indicators according to wealth quintiles, especially for contraceptive use, in 46 low- and middleincome countries based on national population-based surveys conducted between 1990 and 2013. It focuses on the gaps between the poorest and richest quintiles in the earliest and latest survey rounds across a number of reproductive health indicators related to family planning, fertility desires, antenatal care, and infant and child mortality, as well as on improvements in the absolute levels of contraceptive use by the poorest quintile. Gap changes were decomposed to show how the gaps can either diminish or grow due to either the bottom or top quintile, or both. In addition, bivariate correlation analysis was conducted to examine the relationship of the gaps, and of contraceptive use by the poor, to national family planning program efforts. Overall, the gaps between the poorest and richest have narrowed, due primarily to faster improvements among the poor than the rich. For example, the gap between the richest and poorest in the modern contraceptive prevalence rate has declined by $25 \%$, from a 20.4 percentage point difference to a 15.4 point difference. And the gap has decreased more where family planning programs have been stronger. Across most of 18 other reproductive health indicators, the gaps have also been narrowing. For instance, the poor-rich gap for antenatal care decreased by over a third, from a difference of 30.7 percentage points to 19.6 percentage points. Gaps in infant and child mortality also have declined by about one-third. The pattern for contraceptive use in sub-Saharan Africa, however, has been mixed, with the gap actually increasing in some countries with strong programs. This disparity may largely reflect that family planning in the region is generally at an earlier stage in its history, and so programs may initially be reaching better-off clients, especially in urban areas. To promote additional equity, programs should emphasize efforts to increase access to voluntary family planning services to the least well-off, including those in rural and peri-urban areas.
\end{abstract}

\section{INTRODUCTION}

W hile several indicators for reproductive health have improved for entire populations, the gaps between the poor and the rich are another matter. This article assesses the gaps between the poor and the rich regarding contraceptive use and selected reproductive

a Demographic consultant.

Correspondence to John Ross (rosshome8@frontiernet.net). health topics. The core question is whether the serious gaps between the poor and rich in measures of reproductive health have diminished over time and, if so, whether this is due to absolute improvements among the poor.

There is rather little literature on these topics. Some documentation is available on the actual differences among quintiles for reproductive health services. For example, Singh, Darroch, and Ashford show the 
systematic gradient across the 5 wealth quintiles for delivery in a health facility and for care for sexually transmitted infections (STIs) or STI symptoms. ${ }^{1}$ The series of national Demographic and Health Survey (DHS) reports include quintile differences for a range of indictors; see, for example, the initial tables on "Characteristics of Survey Respondents." ${ }^{2}$ However, few analyses are available for trends over time in the poor-rich gaps.

Gakidou and Vayena, writing in 2007, compared modern contraceptive use by the poorest quintile with national averages of use. ${ }^{3}$ They found that modern contraceptive use by the poor remained quite low even while use nationally was rising: "Over time the gaps in use persist and are increasing." The authors conclude, "The secular trend of increasing rates of modern contraceptive use has not resulted in a decrease of the gap in use ..." While they did not study the trend or gaps for all contraceptive use, only modern use, at least as of 2007 the broad nature of the findings would probably not be much different for all use. However, the use of traditional methods may be relatively greater among the poor and among rural populations, which would lessen the gap for all use.

Another analysis, by Hosseinpoor and colleagues, ${ }^{4}$ argues that multiple indicators of health inequality should be used and that both gaps and absolute measures of inequality should be examined. Besides wealth quintiles, differences in residence, education, and gender should be considered to capture inequality. Moreover, since there are numerous dimensions to health inequality, proportional improvements in each should be the focus rather than any single standard. They illustrate the use of both absolute and relative inequalities in 30-31 countries for antenatal care received and births attended by health personnel, using DHS and other surveys conducted between 1993 and 2011 (9- to 11-year

Improvements in reproductive health status over time have generally occurred faster among the least advantaged, but large gaps remain, finds a recent WHO study. is examined especially according to education differentials. In general, improvements over time have occurred faster among the least advantaged, but large gaps remain.

A predecessor of wealth quintiles is the possession of modern objects to assess personal socioeconomic status. This method was used as early as 1963, in a large-scale experiment of family planning adoption in Taichung, Taiwan. Freedman and Takeshita asked respondents whether they owned any of 9 objects such as a bicycle, radio, or sewing machine. ${ }^{6}$ The authors found close correlations between the number of modern objects owned and ever use of contraception or abortion, as well as attitudes toward traditional family values.

The purpose of this article, as stated above, is to examine wealth gaps over time in low- and middle-income countries regarding a number of reproductive health indicators, especially contraceptive use, using national population-based surveys conducted between 1990 and 2013.

\section{DATA AND METHODS}

The data sets used here come from the DHS series, which offers standardized tabulations with wealth quintiles that are not available in other sources such as the Reproductive Health Surveys (RHS) or the Multiple Indicator Cluster Survey (MICS) series. All data were accessed online through the DHS Program STATcompiler (www. statcompiler.com), which contained 249 surveys as of April 2015. Of these, 62 lacked breakdowns by quintiles and 25 countries had only a single survey, leaving 162 surveys (for 46 different countries). The analyses here compare the earliest survey to the most recent survey in each country (total of 92 surveys) to capture the maximum time interval in which changes could be observed (Table 1).

The intervals between the paired surveys for each country varied, averaging 14 years of observation time. The set of 92 surveys occurred between 1990 and 2013, with 2002 as the midpoint. The interquartile range was between 11 years and 16.5 years, so half of the surveys were clustered within that interval of 5.5 years. The 46 countries included the largest ones of Bangladesh, India, Indonesia, Nigeria, and Pakistan as well as numerous middle-sized ones; altogether they contain two-thirds $(67.3 \%)$ of the developing world's population outside of China. (However, each country has equal importance in 


\begin{tabular}{|c|c|c|c|c|c|}
\hline Region/Country & Initial Survey Year & Latest Survey Year & Region/Country & Initial Survey Year & Latest Survey Year \\
\hline \multicolumn{3}{|c|}{ sub-Saharan Africa } & \multicolumn{3}{|c|}{ North Africa/West Asia } \\
\hline Benin & 1996 & 2006 & Armenia & 2000 & 2010 \\
\hline Burkina Faso & $1998-99$ & 2010 & Egypt & 1995 & 2008 \\
\hline Cameroon & 1991 & 2011 & Jordan & 1990 & 2009 \\
\hline Chad & $1996-97$ & 2004 & Morocco & 1992 & 2003-04 \\
\hline Côte d'Ivoire & 1994 & $2011-12$ & Central Asia & & \\
\hline Eritrea & 1995 & 2002 & Kazakhstan & 1995 & 1999 \\
\hline Ethiopia & 2000 & 2011 & \multicolumn{3}{|c|}{ South \& Southeast Asia } \\
\hline Gabon & 2000 & 2012 & Bangladesh & 1993-94 & 2011 \\
\hline Ghana & 1993 & 2008 & Cambodia & 2000 & 2010 \\
\hline Guinea & 1999 & 2005 & India & $1992-93$ & $2005-06$ \\
\hline Kenya & 1993 & $2008-09$ & Indonesia & 1997 & 2012 \\
\hline Lesotho & 2004 & 2009 & Nepal & 1996 & 2011 \\
\hline Madagascar & 1997 & 2008 & Pakistan & $1990-91$ & $2012-13$ \\
\hline Malawi & 1992 & 2010 & Philippines & 1993 & 2008 \\
\hline Mali & $1995-96$ & 2006 & Viet Nam & 1997 & 2002 \\
\hline Mozambique & 1997 & 2011 & \multicolumn{3}{|c|}{ Latin America \& Caribbean } \\
\hline Namibia & 1992 & $2006-07$ & Bolivia & 1994 & 2008 \\
\hline Niger & 1998 & 2006 & Colombia & 1990 & 2010 \\
\hline Nigeria & 1990 & 2008 & Dominican Republic & 1996 & 2007 \\
\hline Rwanda & 1992 & 2010 & Guatemala & 1995 & 1998-99 \\
\hline Senegal & 1997 & 2010-11 & Haiti & $1994-95$ & 2012 \\
\hline Tanzania & 1996 & 2010 & Honduras & $2005-06$ & $2011-12$ \\
\hline Uganda & 1995 & 2011 & Nicaragua & 1998 & 2001 \\
\hline Zambia & 1996 & 2007 & Peru & $1991-92$ & 2012 \\
\hline Zimbabwe & 1994 & 2010-11 & & & \\
\hline
\end{tabular}

the averages below since the averages are not weighted by population size.)

Limitations of the data occur partly because STATcompiler offers quintile breakdowns only on selected variables; nevertheless the variety is fairly inclusive. Some country questionnaires omit questions on a variable so that a few tabulations are for only 42 to 45 countries rather than 46; for example, the question for "ever had sex" was omitted in several countries. A few measures of potential interest are not included for lack of available quintile breakdowns, for example, the proportion of demand for contraception not yet satisfied by modern methods. ${ }^{7}$

\section{Dependent Variables}

The contraceptive prevalence rate $(\mathrm{CPR})$, which includes use of any type of contraceptive method, 
was analyzed for currently married women ages 15-49. We also analyzed the modern contraceptive prevalence rate $(\mathrm{mCPR})$, which includes all methods except the "traditional" ones of rhythm and withdrawal. Here, we follow the DHS specifications of modern methods; they are the sum of male and female sterilization, intrauterine devices (IUDs), oral contraceptive pills, injectables, implants, male and female condoms, diaphragm/ foam/jelly, the lactational amenorrhea method (LAM), the Standard Days Method (SDM), and "other" modern methods. However, across all DHS surveys, 5 of these methods (pills, IUDs, injectables, male condoms, and female sterilization) account for $96 \%$ of all modern method use.

We also explored 18 additional indicators to

Poor-rich gaps were examined for the CPR, mCPR, and 18 other reproductive health indicators. document whether any progress has been made in past years across a broad range of reproductive health concerns. The 18 indicators, along with the DHS definitions, are:

1. Antenatal care (ANC): percent distribution of live births in the 3 years (or in some surveys, 5 years) preceding the survey by source of ANC during pregnancy; also percent distribution of women who had a live birth in the 3 (5) years preceding the survey by number of ANC visits and by the timing of the first visit. The analyses here use only the percentage who had no ANC visits.

2. Signs of pregnancy complications: among women receiving antenatal care, percentage informed of signs of pregnancy complications.

3. Receipt of iron or syrup: percentage of women with a live birth in the 3 (5) years preceding the survey who received iron tablets or syrup or anti-malarial drugs for the most recent birth.

4. Receipt of tetanus injections: percent distribution of last live birth in the last 3 (5) years preceding the survey by number of tetanus toxoid injections given to the mother during pregnancy.

5. Place of delivery: percent distribution of live births in the last 3 (5) years preceding the survey, by place of delivery.

6. Assistance during delivery: percent distribution of live births in the last 3 (5) years preceding the survey, by type of assistance during delivery.

7. Distance problems: percentage of women who reported they have big problems in accessing health care for themselves when they are sick, by type of problem.

8. Perinatal mortality: number of stillbirths and early neonatal deaths, for the 5-year period preceding the survey.

9. Infant mortality: percent of births dying within the first year of life.

10. Under-5 mortality: percent of births dying within the first 5 years of life.

11. Total wanted fertility rate: for the 3 years preceding the survey. Similar to the total fertility rate but excludes unwanted births.

12. Total fertility rate: for the 3 years preceding the survey.

13. Want to limit childbearing: percentage of currently married women who want no more children by number of living children.

14. Ideal number of children: percent distribution of currently married women by ideal number of children, according to number of living children.

15. Ideal number of children at age 20-24: ideal number of children for currently married women aged 20-24.

16. Unmet need for family planning: percentage of currently married women with unmet need for family planning, i.e., the percentage of women currently married or in union who are fecund and who desire to either stop or postpone childbearing, but who are not currently using a contraceptive method.

17. Unmet need for limiting: separates women with unmet need for those who wish to stop future childbearing.

18. Unmet need for spacing: separates women with unmet need for those who wish to postpone the next birth; usually defined as at least 2 years later.

\section{Independent Variables}

One analysis in this article examines the relationship of gaps in contraceptive use to the efforts of national family planning programs. The latter are measured in a series of studies in some 80 developing countries through ratings by local experts and are available approximately 5 years apart from 1982 through 2014. Termed the Family Planning Program Effort Index, the ratings comprise 31 items under the 4 components of policies, services, evaluation, and access 
to methods. A total score is included as the average of the 31 items, as well as summary scores for each of the 4 components. Details are given in a series of publications on the various rounds. ${ }^{8}$

The analysis here used the Family Planning Program Effort Index cycles from 1994 through 2009, and it focused on the total score as well as the specific access score as a more immediate measure of provision of contraceptive supplies and services to the general population.

In relating gaps in contraceptive use to program effort, it is awkward to align the dates for the 2 measures, since the program effort studies occurred at fixed dates whereas the gaps are measured in surveys that were conducted at different dates and at different intervals. The surveys occurred between 1990 and 2013, so one way to explore the relationships is to examine the correlations between the gaps and all of the program cycles from 1994 through 2009, which occurred at the approximate midpoints of many survey intervals. This was done in relation to both the CPR and to the mCPR.

The analysis of contraceptive use gaps and family planning program efforts considers the sub-Saharan African region separately from the other countries due to the region's special character and because its levels of contraceptive use are low, which tends to constrain the size of gaps in use between the poor and the rich. Of the 46 countries, 25 were in sub-Saharan Africa and 21 elsewhere (8 in Latin America, 8 in South and Southeast Asia, 4 in North Africa/West Asia, and $\mathrm{l}$ in the Central Asia Republics). Those 21 countries outside sub-Saharan Africa were combined since the individual numbers were too small for separate estimates.

The wealth index is a composite measure of a household's living standard, using its ownership of selected assets such as bicycles and televisions; materials used in the housing construction; and types of water access and sanitation facilities. ${ }^{9}$ The index itself is divided into quintiles, then each household is scored on each of the index's components to obtain the overall rating. The overall rating assigns the household to 1 of the 5 parts of the index. (Because the quintiles are defined on the weighted index, the final country distribution can differ from $20 \%$ of households in each quintile; however, generally the differences are small.) Finally, the household rating is applied to each individual member. The various DHS reports compare the influence of wealth on various population, health, and nutrition indicators, as noted above. For example:

- In Nigeria, children from the wealthiest households are nearly 15 times more likely to be vaccinated than those from the poorest households ( $58 \%$ vs. $4 \%$ are fully immunized, respectively). ${ }^{10}$

- In the Philippines, $96 \%$ of women in the wealthiest households are assisted by a health professional at delivery, compared with only $42 \%$ of women in the poorest households. ${ }^{11}$

- In Tanzania, HIV prevalence is nearly 2 times higher among women in the wealthiest households $(8.0 \%)$ compared with those in the poorest households $(4.8 \%) .^{12}$

The wealth index is particular to each country, and the 5 quintiles are relative to each other, not to any international standard. Since they are gauged within each country, the absolute levels of poverty in the poorest quintile can be different from those in a neighboring country. However, Winfrey and colleagues have produced a standardized version of the wealth index that allows for comparisons across time for countries and across countries for any point in time. ${ }^{13}$ (See Rutstein and Staveteig for an earlier analysis. ${ }^{14}$ ) Winfrey and colleagues have used the standardized version to disaggregate the contribution of improvements in family planning for women at particular levels of economic status versus the improvements in overall economic status. This unusual effort echoes the call by Hosseinpoor and colleagues ${ }^{4}$ for attention to cross-country criteria.

Unlike the intermediate quintiles, the top and bottom ones include the extreme cases. That is, the wealth range within the top group can contain exceptionally well-off persons, and the bottom group can contain the most desperately poor. All quintile comparisons in this article are between the poorest and the wealthiest quintiles; preliminary tabulations were done to broaden the view to compare the bottom 2 quintiles to the top 2 quintiles. Those results closely paralleled the ones for the bottom vs. the top; only the contrasts were reduced (softened) compared with those between the bottom alone and the top alone.

All 5 quintiles can be examined through other techniques that examine the interplay of all 5 quintiles, but this analysis uses the simpler approach of comparing the poorest and the richest, which also reflects the focus of current discussions.
The Family Planning Program Effort Index measures program efforts across policies, services, evaluation, and access to methods. 
Any of the available measures of inequality can be studied in relationship to such determinants as the nation's modernization or urbanization levels, the allocation of public resources, or other characteristics.

\section{Data Analysis}

For each feature of reproductive health examined, the analysis started with the values for all 5 quintiles, in the initial and latest surveys for each country. Next, the differences between the bottom and top quintiles in the initial and latest survey rounds were calculated to highlight the gap between the poor and the rich, along with the improvement in the gap. Further analysis was then conducted to decompose the gap changes, to show how they can either diminish or grow, due to changes in either the bottom or top quintile. In addition, for contraceptive use, an analysis explored how large the absolute increase in use was among those in the poorest wealth quintile; for both the CPR and the MCPR, ratios of the starting level to the ending level were calculated for each country, and then mean and median ratios for each region and for all 46 countries combined were calculated. Bivariate correlation analysis was performed to explore the relationship between contraceptive use gaps and family planning program effort.

\section{FINDINGS}

\section{Contraceptive Use by Wealth Quintile}

For all 46 countries included in the analysis, CPR increased with increasing wealth quintile (Figure 1). For example, among married women in the lowest quintile, the CPR was $21 \%$ in the initial survey rounds, and it grew to $32 \%$ in the latest surveys. Among the highest wealth quintile, the CPR was $45 \%$ in the initial surveys, growing to $51 \%$ in the latest surveys.

The gap between the poor and the rich in contraceptive use has in fact declined over the

\section{FIGURE 1. Contraceptive Prevalence Rates at Initial and Latest Surveys, ${ }^{a}$ by Wealth Quintile, 46 Low- and Middle-} Income Countries

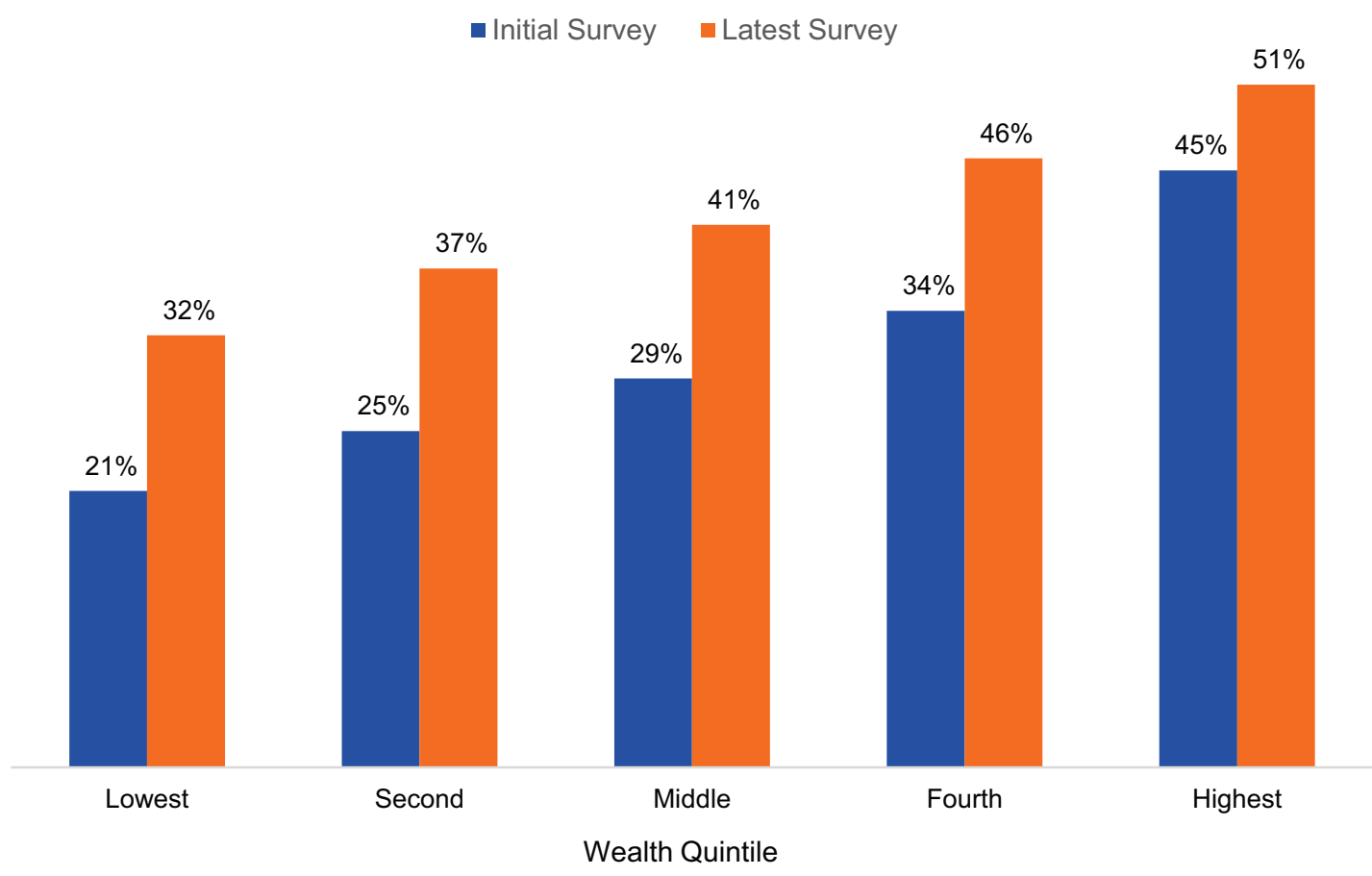

a Survey years varied by country, ranging from 1990 in the initial surveys to 2013 in the latest surveys. 
years. In the initial survey rounds, the CPR gap between the highest and lowest wealth quintile was 24 percentage points (Figure 2). In the latest survey rounds, the CPR gap shrunk by 5 points, for a 19-percentage point difference between the highest and lowest wealth quintiles.

\section{Decomposition of Gap Changes}

In what ways can the gaps change, either growing or shrinking? A gap change is the net result of moves by either or both of the 2 quintiles being compared. It can come from an up or down move by the poor quintile and/or by the rich quintile.

Table 2 illustrates, for the CPR and MCPR, the ways in which a gap may increase (Ethiopia) or decline (Eritrea). The decomposition of the rising gap in Ethiopia shows CPR gains in both quintiles, but a far larger one in the rich quintile: 23.5 vs. only 9.8 in the poor quintile, so the gap increased by nearly 14 points. Eritrea illustrates a reverse dynamic, in which the CPR fell in both quintiles, but more so in the rich quintile: 5.1 vs. 0.8 in the poor quintile, shrinking the gap by 4.3 points. Parallel results occurred for the MCPR.

The type of change is decomposed for all 46 countries in Table 3. Countries are divided into those with increasing gaps (12 countries) and those with decreasing gaps (34 countries). The rows further separate countries by whether both rates fell, or both rose, or showed a mixed combination. In each cell, Q1 refers to the poorest quintile and Q5 to the richest quintile. For example, in the first row the CPR in both quintiles fell, but the CPR in the wealthiest quintile fell more, thereby shrinking the gap.

The second row of Table 3 contains 33 countries, 7 cases in which the gap worsened as contraceptive use among the rich rose faster than among the poor. However, in the majority (26 of 46 countries, or $57 \%)$, the poor increased contraceptive use faster than the rich did. The third row shows 5 countries in which use fell among the poor and rose among the rich, enlarging the gap, together with 6 countries in which the opposite occurred, reducing the gap.

In short, a diverse picture emerges for the ways in which the CPR gap can rise or fall over time. Mainly, however, the CPR gap has fallen as contraceptive use has increased faster among the poor than among the rich.

In absolute terms for the CPR itself, 39 of 46 cases $(85 \%)$ can be viewed as having favorable results for the poor; the CPR rose among both poor and rich in 33 countries and among the poor but not the rich in 6 more.

Note that all countries with increasing gaps, in the first column, are in sub-Saharan Africa except Armenia. It is likely that contraceptive use has spread more rapidly in the cities than in the rural areas, which overlap with the bottom quintile. Again however, in absolute terms contraceptive use in 7 of the 12 countries has risen among both the poor and the rich.

\section{Gaps and Gap Improvements for Contraceptive Use}

The gap between the richest and the poorest quintiles for contraceptive use has been shrinking overall, for both the CPR and the MCPR (Table 4, last row).

For the CPR, the decline of 5.7 points against the starting level of 24.3 represents a $23 \%$ fall in the CPR gap, and the decline of 5.0 points on the starting mCPR level of 20.4 is a $25 \%$ fall in the mCPR gap. The average interval between surveys is 14 years, which converts the declines to $0.41(5.7 / 14)$ and 0.36 points (5.0/14) per year, respectively.

FIGURE 2. Gap (in Percentage Points) Between Richest and Poorest Quintiles in the Contraceptive Prevalence Rate, and Gap Reduction From Initial to Latest Survey, 46 Low- and MiddleIncome Countries

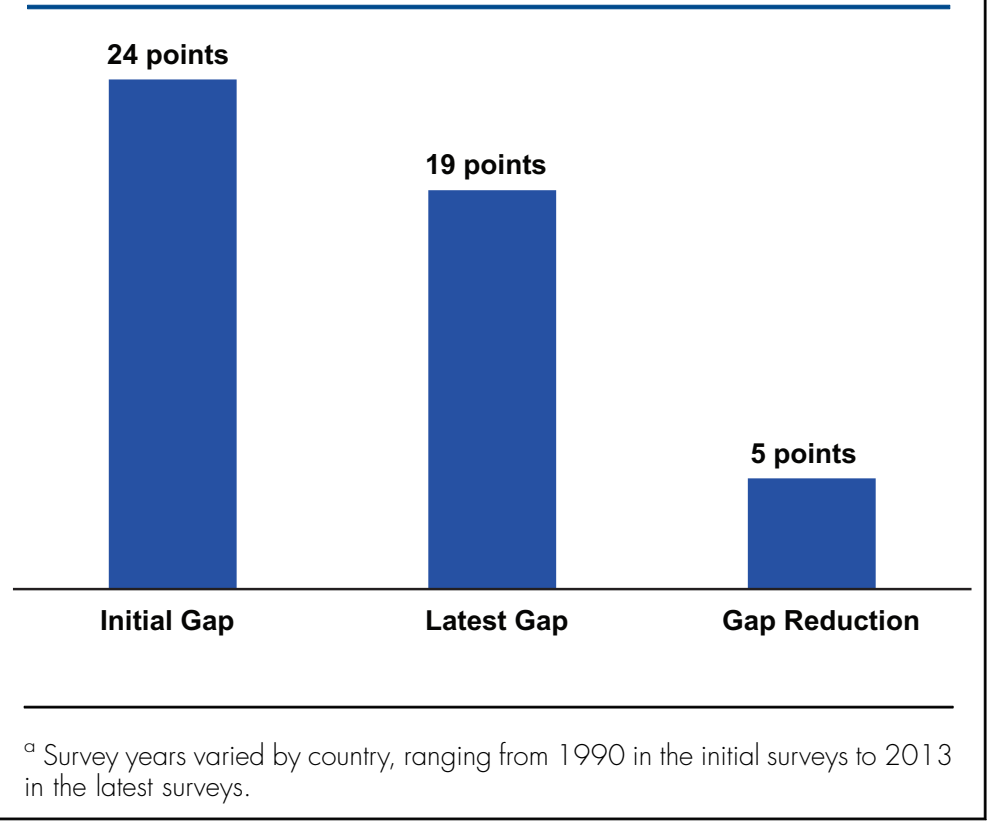

Gaps between the poor and the rich in contraceptive use have declined over the years.

The poor increased contraceptive use faster than the rich did in the majority of countries examined.

The poor-rich gap for modern contraceptive use overall has declined by $25 \%$. 
TABLE 2. Two Types of Changes ${ }^{a}$ in Quintile Gaps for Contraceptive Use, Illustrative Examples From Ethiopia and Eritrea

Ethiopia: Rising Gaps Eritrea: Declining Gaps

Gap at Initial Survey Gap at Latest Survey Gap Change Gap at Initial Survey Gap at Latest Survey Gap Change

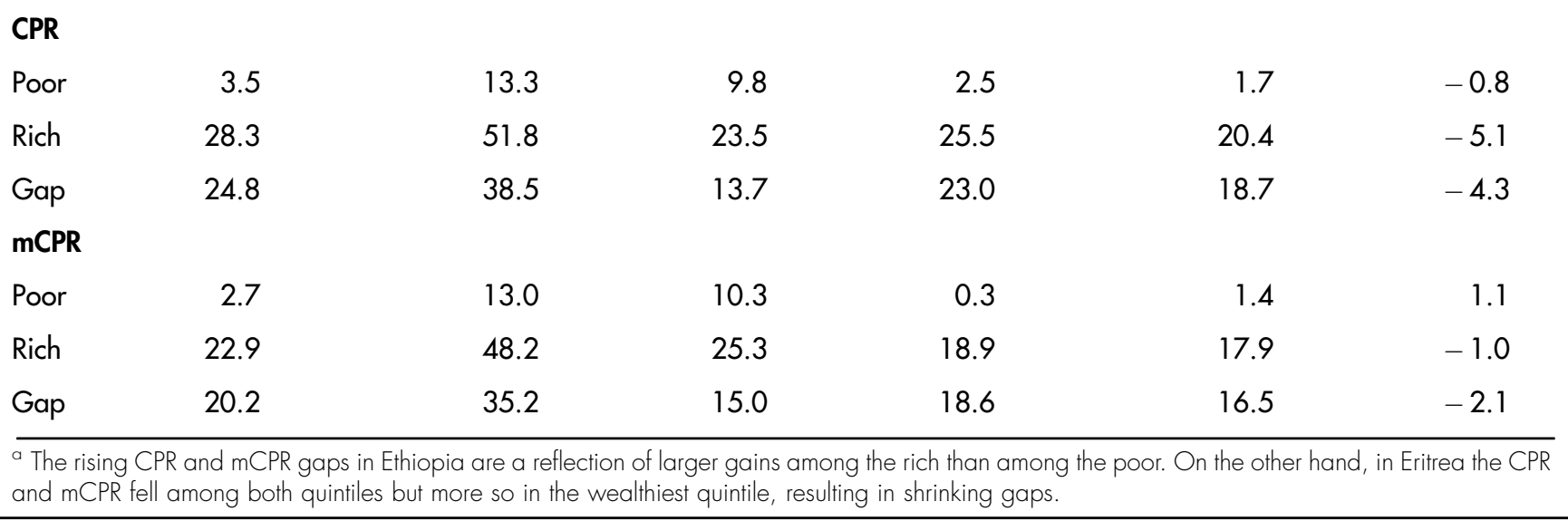

The average gap change in contraceptive use overall in subSaharan Africa has been relatively static.
Sub-Saharan Africa is different: the average gap change for its 25 countries has been nearly zero. There is diversity, however; 10 countries show a worsening gap for the CPR ( 12 for the mCPR), in some cases by a considerable margin of 10 or more points, while the other 15 countries show lessening gaps. The picture is mixed, as it is for the other regions.

However, the other regions have experienced appreciable improvements in their gaps (leaving Central Asia aside with only Kazakhstan): changes of 14.0 (CPR) and 12.9 (mCPR) points in North Africa/West Asia, 9.8 and 10.6 points, respectively, in South and Southeast Asia, and 15.7 and 12.1 points, respectively, in Latin America and the Caribbean. Over 14 years, the annual paces for the CPR are 1.0 for North Africa/ West Asia, 0.70 for South and Southeast Asia, and 1.1 for Latin America and the Caribbean, and $0.92,0.76$, and 0.86 , respectively, for the MCPR (not shown).

Again, the picture is uneven: among countries, the smallest gap changes for the MCPR in these regions (excluding sub-Saharan Africa and Central Asia) range from -2.6 to 3.2; numerous others are about 8.0 to 11.2 ; and others exceed 15, with highs at 25.0 in Morocco, 21.0 in Colombia, and 20.2 in Peru.

Each measure, the CPR and the MCPR, has its own story to tell. Where the CPR gap closed more than the mCPR one did, equity for the use of traditional methods improved in addition to the improvement for modern methods, a welcome outcome. But where the mCPR gap improved more, the equity improvement for traditional methods was less; in fact if the CPR and MCPR gap reductions were equal there was no gap reduction in traditional method use. In Table 4, 13 of the 46 countries show a larger improvement for the mCPR than for the CPR, whereas in 16 other countries the CPR improvement was greater, reflecting an improvement for traditional methods in addition to that for modern methods. Most of the other countries show mixed patterns, with a worsening gap in either the CPR or mCPR or both. In some cases the CPR improved while the mCPR did not, so the improvement in the traditional method gap more than compensated for the worsening mCPR gap.

There is also substantial diversity in the sizes of the gaps themselves (not the gap changes), whether at the initial or latest surveys. Where contraceptive use has reached moderately high levels in the general population, the gap between rich and poor can be quite large, as in Kenya, Lesotho, Madagascar, and Namibia, ranging from 37 to nearly 50 points for the gaps in the CPR in the initial surveys, and none of these have shrunk very much.

Appendix 1 and Appendix 2 provide the full set of CPR and MCPR values, respectively, in the initial and latest surveys for each of the 46 countries by 
TABLE 3. List of Countries According to Type of Change in the CPR Gap and CPR Decrease or Increase Between Surveys, Q1 (Poorest) Compared With Q5 (Richest)

\begin{tabular}{|c|c|c|c|c|}
\hline & Increasing CPR Gap & Decreasing CPR Gap & & TOTAL \\
\hline \multirow[t]{3}{*}{ Both rates fell } & 0 & Q1 fell; Q5 fell more: 2 & & 2 \\
\hline & & Eritrea & & \\
\hline & & Senegal & & \\
\hline \multirow[t]{14}{*}{ Both rates rose } & Q1 rose; $Q 5$ rose more: 7 & Q1 rose; $Q 5$ rose less: 26 & & 33 \\
\hline & Ethiopia & Bangladesh & Kenya & \\
\hline & Guatemala & Bolivia & Lesotho & \\
\hline & Mozambique & Cambodia & Madagascar & \\
\hline & Nigeria & Colombia & Malawi & \\
\hline & Rwanda & Côte d'lvoire & Morocco & \\
\hline & Tanzania & Dominican Rep. & Namibia & \\
\hline & Uganda & Egypt & Nepal & \\
\hline & & Guinea & Nicaragua & \\
\hline & & Haiti & Pakistan & \\
\hline & & Honduras & Peru & \\
\hline & & India & Philippines & \\
\hline & & Jordan & Zambia & \\
\hline & & Kazakhstan & Zimbabwe & \\
\hline \multirow[t]{7}{*}{ Mixed } & Q1 fell; Q5 rose: 5 & Q1 rose; Q5 fell: 6 & & 11 \\
\hline & Armenia & Gabon & & \\
\hline & Benin & Ghana & & \\
\hline & Burkina Faso & Indonesia & & \\
\hline & Cameroon & Mali & & \\
\hline & Chad & Niger & & \\
\hline & & Viet Nam & & \\
\hline TOTAL & 12 & 34 & & 46 \\
\hline
\end{tabular}

region, for the lowest and highest quintiles with the changes, the gap, and the gap reduction.

\section{Absolute Increases in Contraceptive Use by the Poorest Quintile}

It is good news that the gaps in use between the poorest and wealthiest are narrowing, but how large is the absolute increase in use among the poorest? Gaps can narrow simply because contraceptive use declines among the wealthiest, as noted previously. Table 5 provides the absolute increases in use for both the CPR and the mCPR among those in the poorest quintile, as well as the ratios between the starting and ending levels, by region. Note that each ratio shown is the average of all 46 individual country ratios, so it does not necessarily reconcile with the overall starting and ending levels in each row. It is 
TABLE 4. Initial and Latest Gaps (in Percentage Points) Between Richest and Poorest Quintiles and Gap Changes Between Initial and Latest Survey, for the Contraceptive Prevalence Rate (CPR) and Modern Contraceptive Prevalence Rate (mCPR), 46 Low- and Middle-Income Countries

\begin{tabular}{|c|c|c|c|c|c|c|}
\hline \multirow[b]{2}{*}{$\begin{array}{l}\text { Country, } \\
\text { Latest Survey Year }\end{array}$} & \multicolumn{3}{|c|}{ CPR } & \multicolumn{3}{|c|}{ mCPR } \\
\hline & $\begin{array}{l}\text { Gap at Initial } \\
\text { Survey }\end{array}$ & $\begin{array}{l}\text { Gap at Latest } \\
\text { Survey }\end{array}$ & $\begin{array}{l}\text { Gap } \\
\text { Change }\end{array}$ & $\begin{array}{c}\text { Gap at Initial } \\
\text { Survey }\end{array}$ & $\begin{array}{l}\text { Gap at Latest } \\
\text { Survey }\end{array}$ & $\begin{array}{l}\text { Gap } \\
\text { Change }\end{array}$ \\
\hline \multicolumn{7}{|l|}{ sub-Saharan Africa } \\
\hline Benin, 2006 & 17.0 & 25.9 & -8.9 & 7.7 & 10.8 & -3.1 \\
\hline Burkina Faso, 2010 & 16.7 & 30.0 & -13.3 & 14.3 & 26.5 & -12.2 \\
\hline Cameroon, 2011 & 31.2 & 38.3 & -7.1 & 11.8 & 23.3 & -11.5 \\
\hline Chad, 2004 & 6.6 & 10.3 & -3.7 & 4.7 & 7.3 & -2.6 \\
\hline Côte d'Ivoire, 2011-12 & 24.5 & 16.3 & 8.2 & 11.4 & 12.2 & -0.8 \\
\hline Eritrea, 2002 & 23.0 & 18.7 & 4.3 & 18.6 & 16.5 & 2.1 \\
\hline Ethiopia, 2011 & 24.8 & 38.5 & -13.7 & 20.2 & 35.2 & -15.0 \\
\hline Gabon, 2012 & 23.1 & 14.9 & 8.2 & 12.6 & 10.0 & 2.6 \\
\hline Ghana, 2008 & 22.4 & 17.2 & 5.2 & 13.7 & 9.0 & 4.7 \\
\hline Guinea, 2005 & 13.4 & 11.8 & 1.6 & 8.2 & 10.0 & -1.8 \\
\hline Kenya, 2008-09 & 37.0 & 34.6 & 2.4 & 34.8 & 31.0 & 3.8 \\
\hline Lesotho, 2009 & 36.9 & 31.6 & 5.3 & 37.8 & 32.3 & 5.5 \\
\hline Madagascar, 2008-09 & 39.9 & 37.4 & 2.5 & 21.5 & 18.8 & 2.7 \\
\hline Malawi, 2010 & 15.9 & 14.3 & 1.6 & 13.3 & 13.5 & -0.2 \\
\hline Mali, 2006 & 19.2 & 15.4 & 3.8 & 14.8 & 13.6 & 1.2 \\
\hline Mozambique, 2011 & 16.8 & 27.4 & -10.6 & 16.0 & 26.6 & -10.6 \\
\hline Namibia, 2006-07 & 48.6 & 39.2 & 9.4 & 51.5 & 38.8 & 12.7 \\
\hline Niger, 2006 & 18.9 & 10.0 & 8.9 & 17.3 & 13.5 & 3.8 \\
\hline Nigeria, 2008 & 18.9 & 31.8 & -12.9 & 11.7 & 19.8 & -8.1 \\
\hline Rwanda, 2010 & 8.8 & 14.0 & -5.2 & 6.3 & 11.1 & -4.8 \\
\hline Senegal, 2010-11 & 20.6 & 19.7 & 0.9 & 22.6 & 18.5 & 4.1 \\
\hline Tanzania, 2010 & 26.3 & 27.7 & -1.4 & 24.0 & 18.5 & 5.5 \\
\hline Uganda, 2011 & 22.3 & 31.5 & -9.2 & 23.7 & 26.4 & -2.7 \\
\hline Zambia, 2007 & 20.5 & 13.7 & 6.8 & 25.9 & 17.7 & 8.2 \\
\hline Zimbabwe, 2010-11 & 19.5 & 10.3 & 9.2 & 24.6 & 11.2 & 13.4 \\
\hline Mean & 22.9 & 23.2 & -0.3 & 18.8 & 18.9 & -0.1 \\
\hline
\end{tabular}


Table 4 (continued).

\begin{tabular}{|c|c|c|c|c|c|c|}
\hline \multirow[b]{2}{*}{$\begin{array}{l}\text { Country, } \\
\text { Latest Survey Year }\end{array}$} & \multicolumn{3}{|c|}{ CPR } & \multicolumn{3}{|c|}{ mCPR } \\
\hline & $\begin{array}{c}\text { Gap at Initial } \\
\text { Survey }\end{array}$ & $\begin{array}{c}\text { Gap at Latest } \\
\text { Survey }\end{array}$ & $\begin{array}{l}\text { Gap } \\
\text { Change }\end{array}$ & $\begin{array}{l}\text { Gap at Initial } \\
\text { Survey }\end{array}$ & $\begin{array}{l}\text { Gap at Latest } \\
\text { Survey }\end{array}$ & $\begin{array}{l}\text { Gap } \\
\text { Change }\end{array}$ \\
\hline \multicolumn{7}{|l|}{ North Africa/West Asia } \\
\hline Armenia, 2010 & -2.4 & 9.2 & -11.6 & 13.7 & 16.3 & -2.6 \\
\hline Egypt, 2008 & 30.7 & 10.0 & 20.7 & 29.2 & 10.4 & 18.8 \\
\hline Jordan, 2009 & 30.0 & 11.8 & 18.2 & 22.8 & 12.6 & 10.2 \\
\hline Morocco, 2003-04 & 40.4 & 11.6 & 28.8 & 30.4 & 5.4 & 25.0 \\
\hline Mean & 24.7 & 10.7 & 14.0 & 24.0 & 11.2 & 12.9 \\
\hline \multicolumn{7}{|l|}{ Central Asia } \\
\hline Kazakhstan, 1999 & 12.8 & 4.5 & 8.3 & 5.8 & 6.2 & -0.4 \\
\hline \multicolumn{7}{|l|}{ South \& Southeast Asia } \\
\hline Bangladesh, 2011 & 13.3 & -0.7 & 14.0 & 8.2 & -1.8 & 10.0 \\
\hline Cambodia, 2010 & 23.1 & 10.8 & 12.3 & 12.9 & -3.8 & 16.7 \\
\hline India, 2005-06 & 29.7 & 25.3 & 4.4 & 25.7 & 23.4 & 2.3 \\
\hline Indonesia, 2012 & 13.7 & 5.1 & 8.6 & 10.7 & 2.4 & 8.3 \\
\hline Nepal, 2011 & 31.4 & 19.2 & 12.2 & 29.2 & 13.3 & 15.9 \\
\hline Pakistan, 2012-13 & 30.2 & 25.0 & 5.2 & 22.0 & 13.5 & 8.5 \\
\hline Philippines, 2008 & 17.4 & 9.2 & 8.2 & 15.7 & 7.2 & 8.5 \\
\hline Viet Nam, 2002 & 16.9 & 3.2 & 13.7 & 8.5 & -6.3 & 14.8 \\
\hline Mean & 22.0 & 12.1 & 9.8 & 16.6 & 6.0 & 10.6 \\
\hline \multicolumn{7}{|c|}{ Latin America \& Caribbean } \\
\hline Bolivia, 2008 & 45.7 & 24.6 & 21.1 & 39.9 & 23.9 & 16.0 \\
\hline Colombia, 2010 & 30.9 & 4.5 & 26.4 & 27.4 & 6.4 & 21.0 \\
\hline Dominican Rep., 2007 & 13.8 & 5.6 & 8.2 & 12.5 & 2.8 & 9.7 \\
\hline Guatemala, 1998-99 & 60.1 & 64.5 & -4.4 & 51.7 & 54.3 & -2.6 \\
\hline Haiti, 2012 & 23.6 & 1.3 & 22.3 & 16.0 & -2.2 & 18.2 \\
\hline Honduras, 2011-12 & 20.0 & 8.8 & 11.2 & 23.5 & 12.3 & 11.2 \\
\hline Nicaragua, 2001 & 27.0 & 22.0 & 5.0 & 24.0 & 20.8 & 3.2 \\
\hline Peru, 2012 & 36.5 & 1.0 & 35.5 & 37.8 & 17.6 & 20.2 \\
\hline Mean & 32.2 & 16.5 & 15.7 & 29.1 & 17.0 & 12.1 \\
\hline Overall Mean & 24.3 & 18.6 & 5.7 & 20.4 & 15.4 & 5.0 \\
\hline
\end{tabular}


more accurate to rely upon the 46 ratios than upon the relation of the average starting level to the average ending level.

More use of modern methods accounts for nearly all the increase in contraceptive use across regions.
Clearly, the poorest quintile has substantially increased its contraceptive use across regions. Focusing just on the mCPR:

- On average, the MCPR has risen by 13 points, from $14 \%$ of married women using a modern method to $27 \%$. (Total use has risen from $21 \%$ to $33 \%$.)

- Overall, the average ratio of the ending-use level to the starting-use level is 3.5 (mean) or 2.6 (median). Note that these are averages across the individual ratios for the 46 countries, which include some quite high ratios, so the median is preferred (see footnote in Table 5 concerning ratios).

- Modern methods account for nearly all of the increase in contraceptive use. The average rise in modern use, of 12.7 points, slightly exceeds the average rise in all use of 12.3 points. That means that, on average, any substitution of modern for traditional use has been tiny, only 0.4 point.

- Sub-Saharan Africa is special since its startinguse levels were so far below those of the other regions: only $4.6 \%$ of married women used a modern method (mean) or $2.1 \%$ (median). It increased those levels about fourfold between starting and ending. However, a large proportionate increase is easier from a low starting level since a small absolute rise can

TABLE 5. Initial and Latest Levels of Contraceptive Use, by Region, for the Poorest Quintile

\begin{tabular}{lcccccccc}
\hline Region & $\begin{array}{c}\text { Initial CPR } \\
\text { Level }\end{array}$ & $\begin{array}{c}\text { CPR } \\
\text { Rise }\end{array}$ & $\begin{array}{c}\text { Latest CPR } \\
\text { Level }\end{array}$ & $\begin{array}{c}\text { Ratio, } \\
\text { Latest/Initial }\end{array}$ & $\begin{array}{c}\text { Initial } m C P R \\
\text { Level }\end{array}$ & $\begin{array}{c}m C P R \\
\text { Rise }\end{array}$ & $\begin{array}{c}\text { Latest } m C P R \\
\text { Level }\end{array}$ & $\begin{array}{c}\text { Ratio, } \\
\text { Latest/Initial }\end{array}$ \\
\hline
\end{tabular}

Overall

$\begin{array}{lrrrrrrrr}\text { Mean } & 20.6 & 12.3 & 32.9 & 1.9 & 13.8 & 12.7 & 26.5 & 3.5 \\ \text { Median } & 14.6 & 10.6 & 31.8 & 1.7 & 5.5 & 10.3 & 24.3 & 2.6\end{array}$

sub-Saharan Africa

$\begin{array}{lllllllll}\text { Mean } & 9.5 & 7.6 & 17.1 & 2.0 & 4.6 & 9.6 & 14.2 & 4.2 \\ \text { Median } & 8.0 & 4.5 & 13.3 & 2.0 & 2.1 & 6.3 & 11.6 & 3.9\end{array}$

North Africa/West

Asia

Mean

Median

Central Asia

Kazakhstan

South \& Southeast

Asia

Mean

Median

$31.7 \quad 16.0$

28.3

13.2

47.7

1.7

25.7

1.5

20.3

13.5

39.2

1.8

Latin America \&

Caribbean

Mean

33.6

38.9

$\begin{array}{ll}19.1 & 52.8 \\ 18.8 & 53.7\end{array}$

1.9

1.8
24.1

24.1
18.2

42.3

$18.2 \quad 45.1$

Abbreviations: CPR, contraceptive prevalence rate; $\mathrm{mCPR}$, modern contraceptive prevalence rate.

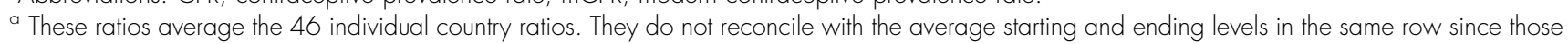
smooth out the overall numerators and denominators of the ratios. It is preferable to use the 46 individual country ratios. 
become a large proportion. Most other regions started much higher and their absolute increases were much larger, yet their ratios are well below those of sub-Saharan Africa, except for the mean of 3.8 in Latin America.

- For total use (CPRs), the ratios are generally lower, principally because the starting levels are higher than for modern use (and in subSaharan Africa, the increases are less than for modern methods).

- Individual countries show substantial variation around each summary (Appendix 1).

\section{Family Planning Program Effort and Gaps in Contraceptive Use}

Can the efforts of national family planning programs reduce gaps in contraceptive use, perhaps by helping the poor increase use faster than among the rich? Bivariate correlation analysis was performed to explore this relationship (Table 6).

A positive " $\mathrm{r}$ " correlation value indicates that a greater gap reduction accompanies greater program effort, generally due to a faster increase in use by the poorest then the richest quintile, shrinking the disparity between the groups.

In sub-Saharan Africa, several points stand out (top of Table 6):

- In the top panel, most correlations are of substantial size, suggesting greater gap reductions accompanying greater program effort. The gaps have narrowed more where program effort has been stronger.

- Most correlations are closer with the mCPRs than with the CPRs, which reflects the focus of national programs on only modern methods.

- Most MCPR correlations are greater with the "Access Scores" than with the "Total Effort Scores" in both 2004 and 2009; they are about equal in 1994 and 1999. Normally we would expect correlations between access and contraceptive use to be relatively close since access is a necessary condition for contraceptive use and the two are intimately connected. However, correlations to gaps rather than levels are a different matter.

- The correlations with the 2004 scores are small, which is something of an anomaly since the correlations before, in 1999, and after, in 2009, are sizeable.

- To augment the analysis, we can examine actual use levels by the poorest quintile in relation to program effort; this follows on the evidence presented previously that the absolute levels of contraceptive use by the poor have risen. Since most gap reductions are due to a faster rise in contraceptive use among the poor than among the rich, how does use by the poor relate to program effort? The right panel of the sub-Saharan Africa section of Table 6 shows the positive relationship, with substantial correlations in all years, although less so for effort in 2004. Where program effort is stronger, use by the poorest quintile is higher. That in turn has translated into the shrinking gaps in contraceptive use between the poor and the rich, as mentioned previously.

For all other countries (lower part of Table 6), the patterns are generally similar, although with less regularity. We place less emphasis on these correlations due to small numbers in each subregion; however, the correlations for the relation of gap reductions to program effort are mostly positive, as they are for access. For unclear reasons, the figures for 1994 are weak, and even negative for access. Greater regularity and higher correlations appear in the right panel of the "all other countries" section, for more contraceptive use by the poor where programs are stronger. The pattern is consistent across all years.

Overall, the starting hypothesis is supported in both regions, that stronger program effort is accompanied by larger reductions in the gaps and by more contraceptive use among the poor that helps explain the gap reductions.

Finally, it is important to recognize that the poorest quintile is dominated, in most countries, by the rural population. The changes noted previously appear to occur disproportionately: "rural" and "poorest quintile" overlap considerably, as seen from two perspectives: (1) the percentage of the total rural population that falls into the bottom quintile, and (2) the percentage of the bottom quintile that is composed of rural people.

To illustrate, with examples taken from 3 DHS surveys in different regions, from the first perspective, in Indonesia, Egypt, and Malawi, 33\%, 30\%, and $23 \%$ of the rural population, respectively, fall into the poorest quintile. The second perspective is more telling: of all women in the poorest quintile, a remarkable $84 \%, 94 \%$, and $98 \%$ live in rural areas, respectively. These high percentages reflect the features of which the wealth index is composed. Rural people are generally disadvantaged when it comes to

\section{Greater family planning program effort was correlated with greater gap reductions in contraceptive use.}


TABLE 6. Correlations ( $r$ Values) for Relation of Family Planning Program Efforts to Gap Changes Between Richest and Poorest Quintiles and to Contraceptive Use by the Poorest, 46 Low- and Middle-Income Countries

\begin{tabular}{|c|c|c|c|c|}
\hline & \multicolumn{2}{|c|}{ Gap Change } & \multirow[b]{2}{*}{ CPR for Poorest Quintile } & \multirow[b]{2}{*}{ mCPR for Poorest Quintile } \\
\hline & CPR & mCPR & & \\
\hline \multicolumn{5}{|c|}{ sub-Saharan Africa ( $\mathrm{N}=25$ Countries) } \\
\hline \multicolumn{5}{|c|}{ Total Effort Score } \\
\hline 2009 & 0.58 & 0.49 & 0.43 & 0.43 \\
\hline 2004 & $(0.04)$ & 0.12 & 0.13 & 0.21 \\
\hline 1999 & 0.26 & 0.39 & 0.36 & 0.42 \\
\hline 1994 & 0.38 & 0.45 & 0.43 & 0.44 \\
\hline Mean & 0.30 & 0.36 & 0.34 & 0.38 \\
\hline \multicolumn{5}{|c|}{ Access Score } \\
\hline 2009 & 0.55 & 0.52 & 0.60 & 0.61 \\
\hline 2004 & 0.09 & 0.25 & 0.24 & 0.29 \\
\hline 1999 & 0.34 & 0.49 & 0.38 & 0.41 \\
\hline 1994 & 0.19 & 0.39 & 0.42 & 0.43 \\
\hline Mean & 0.29 & 0.41 & 0.41 & 0.44 \\
\hline \multicolumn{5}{|c|}{ All Other Countries ( $\mathrm{N}=21$ Countries) } \\
\hline \multicolumn{5}{|c|}{ Total Effort Score } \\
\hline 2009 & 0.25 & 0.41 & 0.32 & 0.47 \\
\hline 2004 & 0.19 & 0.29 & 0.29 & 0.50 \\
\hline 1999 & 0.20 & 0.22 & 0.28 & 0.36 \\
\hline 1994 & $(0.02)$ & - & 0.28 & 0.38 \\
\hline Mean & 0.16 & 0.23 & 0.29 & 0.43 \\
\hline \multicolumn{5}{|l|}{ Access } \\
\hline 2009 & 0.32 & 0.35 & 0.44 & 0.53 \\
\hline 2004 & 0.05 & 0.01 & 0.45 & 0.56 \\
\hline 1999 & 0.32 & 0.09 & 0.40 & 0.26 \\
\hline 1994 & $(0.11)$ & $(0.25)$ & 0.22 & 0.23 \\
\hline Mean & 0.15 & 0.05 & 0.38 & 0.40 \\
\hline
\end{tabular}

the indicators of which the wealth index is composed. Appendix 3 provides fuller details. When we say "bottom quintile," we are most likely saying "rural." As contraceptive use, for example, has risen in the bottom quintile, it has risen primarily among rural residents.
Gaps for Additional Indicators of Reproductive Health

The previous sections have focused in detail on contraceptive use; now we look at 18 additional reproductive health indicators for patterns in the changing gaps between the bottom and top quintiles. 
Among the 18 indicators, most gaps have shrunk, while a few have not changed and 2 have increased (Table 7). In nearly all cases, the initial gap occurs because the poor rating was higher than the rich rating (so nearly all figures are positive). The exception is with desire to limit childbearing, since the rich typically want to limit further childbearing more than the poor do, and the rich are slightly more likely than the poor to say that the last birth was wanted later or not at all.

The overriding finding is that the gaps have diminished on most indicators, which is good news for the field of reproductive health, although the annual pace of improvement may have been slow. In Table 7, the final column shows the percentage declines in the gaps. The annual pace of improvement is not shown; on average, for the 46 countries the interval between surveys is 14 years, but depending on the particular country the interval can be less or more, affecting the annual rate of change in the gap.

For lack of antenatal care, in the initial survey, Gaps in lack of the percentage of poor women who lacked ANC antenatal care altogether was 30.7 percentage points higher than have declined by for rich women (pertains to births within the last over one-third. 3 years). By the time of the most recent surveys, that gap had declined to 19.6 percentage points. Thus, the gap declined by over one-third (11.1/30.7).

The gains have been positive and substantial for the next 3 pregnancy-related services, for being told of possible pregnancy complications, receiving iron or syrup (or in some countries also malaria tablets), and receiving tetanus shots. Next, an exception is delivering in a health facility, but interestingly, the gap for having a skilled attendant at birth has improved, perhaps reflecting

TABLE 7. Gaps Between the Poorest and Richest Quintiles (Poor Minus Rich) at Initial and Latest Survey ${ }^{a}$ and Gap Changes, by Reproductive Health Indicator, 46 Low- and Middle-Income Countries

\begin{tabular}{lcccc}
\hline Reproductive Health Indicator & Gap at Initial Survey & Gap at Latest Survey & Gap Reduction & \% Improvement \\
\hline \% with no antenatal care & 30.7 & 19.6 & 11.1 & 36.1 \\
\% not told of pregnancy complications & 27.9 & 20.9 & 7.0 & 25.1 \\
\% not receiving iron or syrup & 31.7 & 24.3 & 7.4 & 23.2 \\
\% not receiving tetanus & 21.9 & 14.8 & 7.1 & 32.3 \\
\% not delivering in health facility & 48.3 & 49.1 & $10.7)$ & $(1.6)$ \\
\% lacking skilled attendant at birth & 51.4 & 46.8 & 4.6 & 8.9 \\
\% with distance problem & 52.6 & 35.5 & 17.1 & 32.5 \\
Perinatal mortality & 14.4 & 9.6 & 4.8 & 33.1 \\
Infant mortality rate & 37.1 & 24.2 & 13.0 & 34.9 \\
Under-5 mortality rate & 66.8 & 46.8 & 20.0 & 30.0 \\
Total fertility rate & 2.9 & 2.9 & 0.03 & 0.9 \\
Wanted fertility rate & 2.1 & 1.9 & 0.2 & 8.8 \\
Want to limit childbearing & $(7.1)$ & $(2.5)$ & 4.6 & 64.4 \\
Ideal no. of children & 1.38 & 1.28 & 0.10 & 7.4 \\
Ideal no. of children at ages 20-24 & 1.17 & 1.02 & 0.14 & 12.0 \\
Unmet need for family planning & 7.9 & 3.8 & 0.1 & 1.4 \\
Unmet need for limiting & 3.7 & 4.6 & 0.2 & 5.1 \\
Unmet need for spacing & 4.1 & $0.1)$ & $(1.4)$ \\
\hline Survey years varied by country, ranging from 1990 in the initial surveys to 2013 & in the latest surveys. & \\
Note: Data in the last 2 columns were calculated with more decimals than shown and can reflect rounding. & & \\
\end{tabular}




\section{Declining gaps across many indicators are due to faster relative increases by the poor than by the rich.}

\section{Equity between the poor and the rich has improved across a wide range of reproductive health indicators.}

more services at home among the poor. Distance as a serious barrier during sickness has improved sharply, again by about a third (17.1/52.6). Those gains are echoed in narrowed infant and child mortality gaps; they too have declined by about a third.

The gaps between the poor and the rich for the total fertility rate have remained unchanged, at 2.9 births, but the gap in the wanted fertility rate has declined slightly. The original rates that compose the gaps have fallen considerably (not shown); as the earlier sections explain, a gap can increase, decrease, or remain constant while the constituent rates behind the gaps move in various directions.

In Table 7, the gap can be negative if the rich rating is above the poor rating, as with "wanting to limit childbearing" $(7.1 \%)$, since more of the rich wish to limit than the poor do. Then if later the gap narrows, the change itself is positive. Also, where the gap is small to begin with the absolute change is necessarily small, but the percentage change can be large, as also with the item for wanting to limit childbearing. The gaps are small for the ideal number of children and have not varied much over the years, either for all women or for young women aged 25-29. The gap for "ever had sex" is consistent with an earlier onset of sexual activity among the poor.

Finally, gaps in unmet need for family planning have changed very little, while in many countries unmet need overall has declined. All the unmet need gaps are subject to differing rates of change by the poor and the rich, which in turn can reflect a moving balance between increased contraceptive use and a decline in number of children wanted.

\section{DISCUSSION}

Data from 46 low- and middle-income countries show equity improvements across a surprisingly wide range of reproductive health features. Differences have been shrinking between the poor and the rich for contraceptive use, for 5 of 6 major indicators of antenatal and delivery care, for reduced distances to urgent health services, and for infant/child mortality. The gaps have declined as well for the wanted fertility rate and, in smaller degrees, for ideal number of children and unmet need for limiting births. Methodologically, it is straightforward for any country to update or retrace its quintile gaps from a new survey or a review of past ones, and given the data, provincial comparisons are possible.

Gap improvements are not to be confused with general improvements for populations at large. The share held by the poor can remain constant or worsen as overall population rates improve. However, the findings here are that the declining gaps found in many indicators are due to faster relative increases by the poor than by the rich. That reflects improvements in the absolute levels for the poor, which can be separate and even more significant than the gap reductions.

Overall the gaps in the indicators examined have diminished, but the diversity is considerable among regions and, within each region, among countries. For a few indicators, in some countries the gaps have worsened. Especially for the poorest quintile, some sub-Saharan African countries have not done well. However, even in such cases there may be internal contrasts in the levels (rather than the gaps) that suggest some progress, particularly if the levels have risen in each sector. For example, in Nigeria the CPR in cities was about 3 times higher than in the rural sector $(25.9 \%$ vs. $9.4 \%$, respectively) in 2008 , and both had risen from the 2003 survey ( $16.7 \%$ urban and $6.5 \%$ rural, also a threefold difference).

\section{Programmatic Implications}

The analyses above clarify how gap changes can occur in a mechanical sense, i.e., by whether the relative shift is faster in one quintile than another, with changes in either or both quintiles, to go up or down. Behind those trends, however, stand the actual reasons for the substantive changes. Where any quintiles, but especially the poor ones, show improvements, what are the reasons? For contraceptive use, the evidence is that national family planning programs are helpful, and they tend to focus on the general population rather than just on the upper wealth quintiles. It is heartening that the "equity gap" in contraceptive use is narrowing in most countries and narrowing more where program efforts, especially for access to methods, are stronger. This calls for continued and increasing program efforts to advance contraceptive use and to provide more equitable services. However, sub-Saharan Africa is a partial exception, with the overall gap remaining rather constant. And in some countries with notably strong family planning programs (e.g., Ethiopia and Rwanda), the gap actually increased over this time period. This disparity, however, may largely reflect that family planning in sub-Saharan Africa is in general at an earlier stage in its history, in which there is typically more demand for contraception among those who are better off. Further, early program efforts tend to focus on those easiest to reach, particularly in urban areas. And as we have seen, a lack of wealth is highly 
correlated with rural residence, and sub-Saharan Africa is more highly rural than any other region. As programs mature, they are able to serve a broader proportion of the population.

Thus, these findings reinforce the need for strong voluntary family planning programming to reduce gaps further. Where programs are deliberately focused on the rural or the poor, that reinforces the tendency for the bottom to improve faster than the top. The "equity gap" remains sizable in many countries, and programs should emphasize efforts to provide access to the least well-off, including those in rural areas and the poorer parts of urban areas. Examples include mobile outreach and social franchising approaches, which are especially successful in reaching rural and poorer clients, ${ }^{15,16}$ community health workers, vouchers, and use of the "total market approach," which seeks to encourage the better-off to use private-sector services so as to free up public-sector services for less well-off clients. Meanwhile, the poor have been doing better over the past period of about 14 years, although the pace of doing so has been uneven across indicators. Overall, however, the narrowing poor-rich gaps across multiple indicators is rather remarkable.

Acknowledgments: I am especially grateful to James Shelton for important suggestions throughout, and to Albert Hermalin and Tomas Frejka for helpful insights. This article received no funding assistance.

Competing Interests: None declared.

\section{REFERENCES}

1. Singh S, Darroch JD, Ashford LS. Adding it up: the costs and benefits of investing in sexual and reproductive health. New York: Guttmacher Institute; 2014. Co-published by the United Nations Population Fund (UNFPA). Available from: https://www. guttmacher.org/pubs/AddingltUp2014.pdf

2. Demographic and Health Surveys (DHS) Program [Internet]. Rockville (MD): ICF International. DHS final reports; [cited 2015 Aug 8]. Available from: http://dhsprogram.com/publications/ publication-search. $\mathrm{cfm}$ ?type $=5$

3. Gakidou E, Vayena E. Use of modern contraception by the poor is falling behind. PLoS Med. 2007;4(2):e31. CrossRef. Medline
4. Hosseinpoor AR, Bergen N, Koller T, Prasad A, Schlotheuber A, Valentine $N$, et al. Equity-oriented monitoring in the context of universal health coverage. PLoS Med. 2014;11(9):e1001727. CrossRef. Medline

5. World Health Organization (WHO). State of inequality: reproductive, maternal, newborn and child health: interactive visualization of health data. Geneva: WHO; 2015. Available from: http://mww.who.int/ gho/health_equity/report_2015/en/

6. Freedman R, Takeshita JY. Family planning in Taiwan: an experiment in social change. Princeton (NJ): Princeton University Press; 1969.

7. Fabic MS, Choi Y, Bongaarts J, Darroch JE, Ross JA, Stover J, et al. Meeting demand for family planning within a generation: the post2015 agenda. 2014;385(9981):1928-1931. CrossRef. Medline

8. Ross J, Smith E. Trends in national family planning programs, 1999, 2004 and 2009. Int Perspect Sex Reprod Health. 2011; 37(3): 125-133. CrossRef. Medline

9. Rutstein S, Johnson K. The DHS wealth index. DHS Comparative Reports No. 6. Calverton (MD): ORC Macro; 2004. Available from: https://dhsprogram.com/pubs/pdf/CR6/CR6.pdf

10. National Population Commission (NPC) [Nigeria]; ICF International. Nigeria demographic and health survey 2013. Abuja (Nigeria): NPC; 2014. Co-published by ICF International. Available from: http://dhsprogram.com/pubs/pdf/FR293/FR293.pdf

11. Philippine Statistics Authority (PSA); ICF International. Philippines national demographic and health survey. Manila (Philippines): PSA; 2014. Co-published by ICF International. Available from: http://dhsprogram.com/pubs/pdf/FR294/FR294.pdf

12. Tanzania Commission for AIDS (TACAIDS); Zanzibar AIDS Commission (ZAC); National Bureau of Statistics (NBS); Office of the Chief Government Statistician (OCGS); ICF International. Tanzania HIV/AIDS and malaria indicator survey 2011-12. Dar es Salaam (Tanzania): TACAIDS; 2013. Co-published by ZAC, NBS, OCGS, and ICF International. Available from: http:// dhsprogram.com/pubs/pdf/AIS11/AIS1 1.pdf

13. Winfrey W, Davis J, Emmart J, Sonneveldt E. Aftribution of family planning improvements. Report submitted to the Bill and Melinda Gates Foundation; 2014.

14. Rutstein S, Staveteig S. Making the Demographic and Health Surveys wealth index comparable. DHS Methodological Reports No. 9. Rockville (MD): ICF International; 2014. Available from: http://www.dhsprogram.com/pubs/pdf/MR9/MR9.pdf

15. Munroe E, Hayes B, Taft J. Private-sector social franchising to accelerate family planning access, choice, and quality: results from Marie Stopes International. Glob Health Sci Pract. 2015; 3(2):195-208. CrossRef. Medline

16. Duvall S, Thurston S, Weinberger M, Nuccio O, Fuchs-Montgomery N. Scaling up delivery of contraceptive implants in sub-Saharan Africa: operational experiences of Marie Stopes International. Glob Health Sci Pract. 2014;2(1):72-92. CrossRef. Medline

\section{Peer Reviewed}

Received: 2015 Apr 19; Accepted: 2015 Jul 22; First Published Online: 2015 Sep 7

Cite this article as: Ross J. Improved reproductive health equity between the poor and the rich: an analysis of trends in 46 low- and middleincome countries. Glob Health Sci Pract. 2015;3(3):419-445. http://dx.doi.org/10.9745/GHSP-D-15-00124.

(c) Ross. This is an open-access article distributed under the terms of the Creative Commons Attribution License, which permits unrestricted use, distribution, and reproduction in any medium, provided the original author and source are properly cited. To view a copy of the license, visit http://creativecommons.org/licenses/by/3.0/. When linking to this article, please use the following permanent link: http://dx.doi.org/10.9745/GHSP-D-15-00124. 
APPENDIX 1. Contraceptive Prevalence Rate (CPR), CPR Changes, Quintile Gaps, and Changes in Quintile Gaps Between Initial and Latest Survey, 46 Low- and Middle-Income Countries

\begin{tabular}{|c|c|c|c|c|c|c|}
\hline \multirow[b]{2}{*}{ Country, Survey Year } & \multicolumn{2}{|c|}{ Lowest Quintile } & \multicolumn{2}{|c|}{ Highest Quintile } & \multirow[b]{2}{*}{ Quintile Gap } & \multirow[b]{2}{*}{ Gap Change } \\
\hline & CPR & CPR Rise & CPR & CPR Rise & & \\
\hline \multicolumn{7}{|l|}{ sub-Saharan Africa } \\
\hline Benin 2006 & 7.7 & -1.5 & 33.6 & 7.4 & 25.9 & -8.9 \\
\hline Benin 1996 & 9.2 & & 26.2 & & 17.0 & \\
\hline Burkina Faso 2010 & 7.4 & -0.6 & 37.4 & 12.7 & 30.0 & -23.6 \\
\hline Burkina Faso 1998-99 & 8.0 & & 24.7 & & 16.7 & \\
\hline Cameroon 2011 & 2.9 & -1.9 & 41.2 & 5.2 & 38.3 & -7.1 \\
\hline Cameroon 1991 & 4.8 & & 36.0 & & 31.2 & \\
\hline Chad 2004 & 0.0 & -3.5 & 10.3 & 0.2 & 10.3 & -3.7 \\
\hline Chad 1996-97 & 3.5 & & 10.1 & & 6.6 & \\
\hline Côte d'Ivoire 201 1-12 & 11.7 & 8.0 & 28.0 & -0.2 & 16.3 & 8.2 \\
\hline Côte d'Ivoire 1994 & 3.7 & & 28.2 & & 24.5 & \\
\hline Eritrea 2002 & 1.7 & -0.8 & 20.4 & -5.1 & 18.7 & 4.3 \\
\hline Eritrea 1995 & 2.5 & & 25.5 & & 23.0 & \\
\hline Ethiopia 2011 & 13.3 & 9.8 & 51.8 & 23.5 & 38.5 & -13.7 \\
\hline Ethiopia 2000 & 3.5 & & 28.3 & & 24.8 & \\
\hline Gabon 2012 & 21.3 & 2.5 & 36.2 & -5.7 & 14.9 & 8.2 \\
\hline Gabon 2000 & 18.8 & & 41.9 & & 23.1 & \\
\hline Ghana 2008 & 14.2 & 2.4 & 31.4 & -2.8 & 17.2 & 5.2 \\
\hline Ghana 1993 & 11.8 & & 34.2 & & 22.4 & \\
\hline Guinea 2005 & 5.3 & 3.6 & 17.1 & 2.0 & 11.8 & 1.6 \\
\hline Guinea 1999 & 1.7 & & 15.1 & & 13.4 & \\
\hline Kenya 2008-09 & 20.1 & 5.4 & 54.7 & 3.0 & 34.6 & 2.4 \\
\hline Kenya 1993 & 14.7 & & 51.7 & & 37.0 & \\
\hline Lesotho 2009 & 30.1 & 12.5 & 61.7 & 7.2 & 31.6 & 5.3 \\
\hline Lesotho 2004 & 17.6 & & 54.5 & & 36.9 & \\
\hline Madagascar 2008-09 & 19.9 & 14.1 & 57.3 & 11.6 & 37.4 & 2.5 \\
\hline Madagascar 1997 & 5.8 & & 45.7 & & 39.9 & \\
\hline Malawi 2010 & 38.7 & 29.3 & 53.0 & 27.7 & 14.3 & 1.6 \\
\hline Malawi 1992 & 9.4 & & 25.3 & & 15.9 & \\
\hline Mali 2006 & 3.7 & 2.4 & 19.1 & -1.4 & 15.4 & 3.8 \\
\hline Mali 1995-96 & 1.3 & & 20.5 & & 19.2 & \\
\hline
\end{tabular}




\begin{tabular}{|c|c|c|c|c|c|c|}
\hline \multicolumn{7}{|c|}{ APPENDIX 1 (continued). } \\
\hline \multirow[b]{2}{*}{ Country, Survey Year } & \multicolumn{2}{|c|}{ Lowest Quintile } & \multicolumn{2}{|c|}{ Highest Quintile } & \multirow[b]{2}{*}{ Quintile Gap } & \multirow[b]{2}{*}{ Gap Change } \\
\hline & CPR & CPR Rise & CPR & CPR Rise & & \\
\hline Mozambique 2011 & 2.9 & 1.6 & 30.3 & 12.2 & 27.4 & -10.6 \\
\hline Mozambique 1997 & 1.3 & & 18.1 & & 16.8 & \\
\hline Namibia 2006-07 & 31.9 & 22.4 & 71.1 & 13.0 & 39.2 & 9.4 \\
\hline Namibia 1992 & 9.5 & & 58.1 & & 48.6 & \\
\hline Niger 2006 & 10.9 & 7.3 & 20.9 & -1.6 & 10.0 & 8.9 \\
\hline Niger 1998 & 3.6 & & 22.5 & & 18.9 & \\
\hline Nigeria 2008 & 3.2 & 2.3 & 35.0 & 15.2 & 31.8 & -12.9 \\
\hline Nigeria 1990 & 0.9 & & 19.8 & & 18.9 & \\
\hline Rwanda 2010 & 43.1 & 23.6 & 57.1 & 28.8 & 14.0 & -5.2 \\
\hline Rwanda 1992 & 19.5 & & 28.3 & & 8.8 & \\
\hline Senegal 2010-11 & 4.8 & -1.8 & 24.5 & -2.7 & 19.7 & 0.9 \\
\hline Senegal 1997 & 6.6 & & 27.2 & & 20.6 & \\
\hline Tanzania 2010 & 22.9 & 12.8 & 50.6 & 14.2 & 27.7 & -1.4 \\
\hline Tanzania 1996 & 10.1 & & 36.4 & & 26.3 & \\
\hline Uganda 2011 & 14.7 & 4.5 & 46.2 & 13.7 & 31.5 & -9.2 \\
\hline Uganda 1995 & 10.2 & & 32.5 & & 22.3 & \\
\hline Zambia 2007 & 40.5 & 20.5 & 54.2 & 13.7 & 13.7 & 6.8 \\
\hline Zambia 1996 & 20.0 & & 40.5 & & 20.5 & \\
\hline Zimbabwe 2010-11 & 54.3 & 14.2 & 64.6 & 5.0 & 10.3 & 9.2 \\
\hline Zimbabwe 1994 & 40.1 & & 59.6 & & 19.5 & \\
\hline MEAN CHANGES & & 7.6 & & 7.9 & & -0.3 \\
\hline \multicolumn{7}{|l|}{ North Africa/West Asia } \\
\hline Armenia 2010 & 53.2 & -8.4 & 62.4 & 3.2 & 9.2 & -11.6 \\
\hline Armenia 2000 & 61.6 & & 59.2 & & -2.4 & \\
\hline Egypt 2008 & 55.4 & 25.0 & 65.4 & 4.3 & 10.0 & 20.7 \\
\hline Egypt 1995 & 30.4 & & 61.1 & & 30.7 & \\
\hline Jordan 2009 & 53.5 & 29.1 & 65.3 & 10.9 & 11.8 & 18.2 \\
\hline Jordan 1990 & 24.4 & & 54.4 & & 30.0 & \\
\hline Morocco 2003-04 & 58.3 & 38.6 & 69.9 & 9.8 & 11.6 & 28.8 \\
\hline Morocco 1992 & 19.7 & & 60.1 & & 40.4 & \\
\hline MEAN CHANGES & & 21.1 & & 7.1 & & 14.0 \\
\hline
\end{tabular}




\begin{tabular}{|c|c|c|c|c|c|c|}
\hline \multirow[b]{2}{*}{ Country, Survey Year } & \multicolumn{2}{|c|}{ Lowest Quintile } & \multicolumn{2}{|c|}{ Highest Quintile } & \multirow[b]{2}{*}{ Quintile Gap } & \multirow[b]{2}{*}{ Gap Change } \\
\hline & CPR & CPR Rise & CPR & CPR Rise & & \\
\hline \multicolumn{7}{|l|}{ Central Asia } \\
\hline Kazakhstan 1999 & 63.7 & 10.9 & 68.2 & 2.6 & 4.5 & 8.3 \\
\hline Kazakhstan 1995 & 52.8 & & 65.6 & & 12.8 & \\
\hline \multicolumn{7}{|l|}{ South \& Southeast Asia } \\
\hline Bangladesh 2011 & 61.5 & 21.1 & 60.8 & 7.1 & -0.7 & 14.0 \\
\hline Bangladesh 1993-94 & 40.4 & & 53.7 & & 13.3 & \\
\hline Cambodia 2010 & 45.2 & 30.8 & 56.0 & 18.5 & 10.8 & 12.3 \\
\hline Cambodia 2000 & 14.4 & & 37.5 & & 23.1 & \\
\hline India 2005-06 & 42.2 & 14.1 & 67.5 & 9.7 & 25.3 & 4.4 \\
\hline India 1992-93 & 28.1 & & 57.8 & & 29.7 & \\
\hline Indonesia 2012 & 56.2 & 7.9 & 61.3 & -0.7 & 5.1 & 8.6 \\
\hline Indonesia 1997 & 48.3 & & 62.0 & & 13.7 & \\
\hline Nepal 2011 & 40.4 & 22.7 & 59.6 & 10.5 & 19.2 & 12.2 \\
\hline Nepal 1996 & 17.7 & & 49.1 & & 31.4 & \\
\hline Pakistan 2012-13 & 20.8 & 19.2 & 45.8 & 14.0 & 25.0 & 5.2 \\
\hline Pakistan 1990-91 & 1.6 & & 31.8 & & 30.2 & \\
\hline Philippines 2008 & 40.8 & 12.3 & 50.0 & 4.1 & 9.2 & 8.2 \\
\hline Philippines 1993 & 28.5 & & 45.9 & & 17.4 & \\
\hline Viet Nam 2002 & 74.3 & 10.2 & 77.5 & -3.5 & 3.2 & 13.7 \\
\hline Viet Nam 1997 & 64.1 & & 81.0 & & 16.9 & \\
\hline MEAN CHANGES & & 17.3 & & 7.5 & & 9.8 \\
\hline \multicolumn{7}{|c|}{ Latin America \& Caribbean } \\
\hline Bolivia 2008 & 46.2 & 23.6 & 70.8 & 2.5 & 24.6 & 21.1 \\
\hline Bolivia 1994 & 22.6 & & 68.3 & & 45.7 & \\
\hline Colombia 2010 & 75.5 & 29.0 & 80.0 & 2.6 & 4.5 & 26.4 \\
\hline Colombia 1990 & 46.5 & & 77.4 & & 30.9 & \\
\hline Dominican Rep. 2007 & 67.5 & 12.7 & 73.1 & 4.5 & 5.6 & 8.2 \\
\hline Dominican Rep. 1996 & 54.8 & & 68.6 & & 13.8 & \\
\hline Guatemala 1998-99 & 8.4 & 1.8 & 72.9 & 6.2 & 64.5 & -4.4 \\
\hline Guatemala 1995 & 6.6 & & 66.7 & & 60.1 & \\
\hline Haiti 2012 & 31.7 & 24.1 & 33.0 & 1.8 & 1.3 & 22.3 \\
\hline Haiti 1994-95 & 7.6 & & 31.2 & & 23.6 & \\
\hline
\end{tabular}




\begin{tabular}{|c|c|c|c|c|c|c|}
\hline \multirow[b]{2}{*}{ Country, Survey Year } & \multicolumn{2}{|c|}{ Lowest Quintile } & \multicolumn{2}{|c|}{ Highest Quintile } & \multirow[b]{2}{*}{ Quintile Gap } & \multirow[b]{2}{*}{ Gap Change } \\
\hline & CPR & CPR Rise & CPR & CPR Rise & & \\
\hline Honduras 2011-12 & 67.3 & 14.0 & 76.1 & 2.8 & 8.8 & 11.2 \\
\hline Honduras 2005-06 & 53.3 & & 73.3 & & 20.0 & \\
\hline Nicaragua 2001 & 52.5 & 10.3 & 74.5 & 5.3 & 22.0 & 5.0 \\
\hline Nicaragua 1998 & 42.2 & & 69.2 & & 27.0 & \\
\hline Peru 2012 & 72.9 & 37.4 & 73.9 & 1.9 & 1.0 & 35.5 \\
\hline Peru 1991-92 & 35.5 & & 72.0 & & 36.5 & \\
\hline MEAN CHANGES & & 19.1 & & 3.5 & & 15.7 \\
\hline OVERALL MEAN CHANGES & & 12.5 & & 6.8 & & 5.4 \\
\hline
\end{tabular}


APPENDIX 2. Modern Contraceptive Prevalence Rate (mCPR), mCPR Changes, Quintile Gaps, and Changes in Quintile Gaps Between Initial and Latest Survey, 46 Low- and Middle-Income Countries

\begin{tabular}{|c|c|c|c|c|c|c|}
\hline \multirow[b]{2}{*}{ Country, Survey Year } & \multicolumn{2}{|c|}{ Lowest Quintile } & \multicolumn{2}{|c|}{ Highest Quintile } & \multirow[b]{2}{*}{ Gap } & \multirow[b]{2}{*}{ Gap Change } \\
\hline & mCPR & mCPR Rise & mCPR & mCPR Rise & & \\
\hline \multicolumn{7}{|l|}{ sub-Saharan Africa } \\
\hline Benin 2006 & 2.4 & 1.1 & 13.2 & 4.2 & 10.8 & -3.1 \\
\hline Benin 1996 & 1.3 & & 9.0 & & 7.7 & \\
\hline Burkina Faso 2010 & 7.1 & 6.3 & 33.6 & 17.2 & 26.5 & -10.9 \\
\hline Burkina Faso 1998-99 & 0.8 & & 16.4 & & 15.6 & \\
\hline Cameroon 2011 & 2.4 & 1.7 & 25.7 & 13.2 & 23.3 & -11.5 \\
\hline Cameroon 1991 & 0.7 & & 12.5 & & 11.8 & \\
\hline Chad 2004 & 0.0 & -0.1 & 7.3 & 2.5 & 7.3 & -2.6 \\
\hline Chad 1996-97 & 0.1 & & 4.8 & & 4.7 & \\
\hline Côte d'lvoire 201 1-12 & 7.4 & 6.3 & 19.6 & 7.1 & 12.2 & -0.8 \\
\hline Côte d'Ivoire 1994 & 1.1 & & 12.5 & & 11.4 & \\
\hline Eritrea 2002 & 1.4 & 1.1 & 17.9 & -1.0 & 16.5 & 2.1 \\
\hline Eritrea 1995 & 0.3 & & 18.9 & & 18.6 & \\
\hline Ethiopia 2011 & 13.0 & 10.3 & 48.2 & 25.3 & 35.2 & -15.0 \\
\hline Ethiopia 2000 & 2.7 & & 22.9 & & 20.2 & \\
\hline Gabon 2012 & 11.9 & 6.3 & 21.9 & 3.7 & 10.0 & 2.6 \\
\hline Gabon 2000 & 5.6 & & 18.2 & & 12.6 & \\
\hline Ghana 2008 & 11.6 & 6.2 & 20.6 & 1.5 & 9.0 & 4.7 \\
\hline Ghana 1993 & 5.4 & & 19.1 & & 13.7 & \\
\hline Guinea 2005 & 2.7 & 1.7 & 12.7 & 3.5 & 10.0 & -1.8 \\
\hline Guinea 1999 & 1.0 & & 9.2 & & 8.2 & \\
\hline Kenya 2008-09 & 16.9 & 6.6 & 47.9 & 2.8 & 31.0 & 3.8 \\
\hline Kenya 1993 & 10.3 & & 45.1 & & 34.8 & \\
\hline Lesotho 2009 & 28.6 & 13.2 & 60.9 & 7.7 & 32.3 & 5.5 \\
\hline Lesotho 2004 & 15.4 & & 53.2 & & 37.8 & \\
\hline Madagascar 2008-09 & 17.6 & 15.3 & 36.4 & 12.6 & 18.8 & 2.7 \\
\hline Madagascar 1997 & 2.3 & & 23.8 & & 21.5 & \\
\hline Malawi 2010 & 34.9 & 31.0 & 48.4 & 31.2 & 13.5 & -0.2 \\
\hline Malawi 1992 & 3.9 & & 17.2 & & 13.3 & \\
\hline Mali 2006 & 2.8 & 2.3 & 16.4 & 1.1 & 13.6 & 1.2 \\
\hline Mali 1995-96 & 0.5 & & 15.3 & & 14.8 & \\
\hline
\end{tabular}




\begin{tabular}{|c|c|c|c|c|c|c|}
\hline \multirow[b]{2}{*}{ Country, Survey Year } & \multicolumn{2}{|c|}{ Lowest Quintile } & \multicolumn{2}{|c|}{ Highest Quintile } & \multirow[b]{2}{*}{ Gap } & \multirow[b]{2}{*}{ Gap Change } \\
\hline & $\mathrm{mCPR}$ & mCPR Rise & mCPR & mCPR Rise & & \\
\hline Mozambique 2011 & 2.9 & 2.0 & 29.5 & 12.6 & 26.6 & -10.6 \\
\hline Mozambique 1997 & 0.9 & & 16.9 & & 16.0 & \\
\hline Namibia 2006-07 & 29.6 & 24.2 & 68.4 & 11.5 & 38.8 & 12.7 \\
\hline Namibia 1992 & 5.4 & & 56.9 & & 51.5 & \\
\hline Niger 2006 & 2.3 & 1.5 & 15.8 & -2.3 & 13.5 & 3.8 \\
\hline Niger 1998 & 0.8 & & 18.1 & & 17.3 & \\
\hline Nigeria 2008 & 2.5 & 2.0 & 22.3 & 10.1 & 19.8 & -8.1 \\
\hline Nigeria 1990 & 0.5 & & 12.2 & & 11.7 & \\
\hline Rwanda 2010 & 38.5 & 26.7 & 49.6 & 31.5 & 11.1 & -4.8 \\
\hline Rwanda 1992 & 11.8 & & 18.1 & & 6.3 & \\
\hline Senegal 2010-11 & 4.4 & 3.4 & 22.9 & -0.7 & 18.5 & 4.1 \\
\hline Senegal 1997 & 1.0 & & 23.6 & & 22.6 & \\
\hline Tanzania 2010 & 19.2 & 14.3 & 37.7 & 8.8 & 18.5 & 5.5 \\
\hline Tanzania 1996 & 4.9 & & 28.9 & & 24.0 & \\
\hline Uganda 2011 & 12.7 & 10.6 & 39.1 & 13.3 & 26.4 & -2.7 \\
\hline Uganda 1995 & 2.1 & & 25.8 & & 23.7 & \\
\hline Zambia 2007 & 30.6 & 25.2 & 48.3 & 17.0 & 17.7 & 8.2 \\
\hline Zambia 1996 & 5.4 & & 31.3 & & 25.9 & \\
\hline Zimbabwe 2010-11 & 52.4 & 21.2 & 63.6 & 7.8 & 11.2 & 13.4 \\
\hline Zimbabwe 1994 & 31.2 & & 55.8 & & 24.6 & \\
\hline MEAN CHANGES & & 9.6 & & 9.7 & & -0.1 \\
\hline \multicolumn{7}{|l|}{ North Africa/West Asia } \\
\hline Armenia 2010 & 21.4 & 5.9 & 37.7 & 8.5 & 16.3 & -2.6 \\
\hline Armenia 2000 & 15.5 & & 29.2 & & 13.7 & \\
\hline Egypt 2008 & 51.9 & 23.7 & 62.3 & 4.9 & 10.4 & 18.8 \\
\hline Egypt 1995 & 28.2 & & 57.4 & & 29.2 & \\
\hline Jordan 2009 & 36.6 & 21.5 & 49.2 & 11.3 & 12.6 & 10.2 \\
\hline Jordan 1990 & 15.1 & & 37.9 & & 22.8 & \\
\hline Morocco 2003-04 & 51.4 & 33.5 & 56.8 & 8.5 & 5.4 & 25.0 \\
\hline Morocco 1992 & 17.9 & & 48.3 & & 30.4 & \\
\hline MEAN CHANGES & & 21.2 & & 8.3 & & 12.9 \\
\hline
\end{tabular}




\begin{tabular}{|c|c|c|c|c|c|c|}
\hline \multirow[b]{2}{*}{ Country, Survey Year } & \multicolumn{2}{|c|}{ Lowest Quintile } & \multicolumn{2}{|c|}{ Highest Quintile } & \multirow[b]{2}{*}{ Gap } & \multirow[b]{2}{*}{ Gap Change } \\
\hline & $\mathrm{mCPR}$ & mCPR Rise & $\mathrm{mCPR}$ & mCPR Rise & & \\
\hline \multicolumn{7}{|l|}{ Central Asia } \\
\hline Kazakhstan 1999 & 48.9 & 5.1 & 55.1 & 5.5 & 6.2 & -0.4 \\
\hline Kazakhstan 1995 & 43.8 & & 49.6 & & 5.8 & \\
\hline \multicolumn{7}{|l|}{ South \& Southeast Asia } \\
\hline Bangladesh 2011 & 52.9 & 18.4 & 51.1 & 8.4 & -1.8 & 10.0 \\
\hline Bangladesh 1993-94 & 34.5 & & 42.7 & & 8.2 & \\
\hline Cambodia 2010 & 35.2 & 22.7 & 31.4 & 6.0 & -3.8 & 16.7 \\
\hline Cambodia 2000 & 12.5 & & 25.4 & & 12.9 & \\
\hline India 2005-06 & 34.6 & 9.7 & 58.0 & 7.4 & 23.4 & 2.3 \\
\hline India 1992-93 & 24.9 & & 50.6 & & 25.7 & \\
\hline Indonesia 2012 & 53.0 & 6.8 & 55.4 & -1.5 & 2.4 & 8.3 \\
\hline Indonesia 1997 & 46.2 & & 56.9 & & 10.7 & \\
\hline Nepal 2011 & 35.6 & 19.9 & 48.9 & 4.0 & 13.3 & 15.9 \\
\hline Nepal 1996 & 15.7 & & 44.9 & & 29.2 & \\
\hline Pakistan 2012-13 & 18.1 & 16.9 & 31.6 & 8.4 & 13.5 & 8.5 \\
\hline Pakistan 1990-91 & 1.2 & & 23.2 & & 22.0 & \\
\hline Philippines 2008 & 25.9 & 10.2 & 33.1 & 1.7 & 7.2 & 8.5 \\
\hline Philippines 1993 & 15.7 & & 31.4 & & 15.7 & \\
\hline Viet Nam 2002 & 57.9 & 10.9 & 51.6 & -3.9 & -6.3 & 14.8 \\
\hline Viet Nam 1997 & 47.0 & & 55.5 & & 8.5 & \\
\hline MEAN CHANGES & & 14.4 & & 3.8 & & 10.6 \\
\hline \multicolumn{7}{|c|}{ Latin America \& Caribbean } \\
\hline Bolivia 2008 & 22.6 & 21.0 & 46.5 & 5.0 & 23.9 & 16.0 \\
\hline Bolivia 1994 & 1.6 & & 41.5 & & 39.9 & \\
\hline Colombia 2010 & 68.5 & 30.8 & 74.9 & 9.8 & 6.4 & 21.0 \\
\hline Colombia 1990 & 37.7 & & 65.1 & & 27.4 & \\
\hline Dominican Rep. 2007 & 66.5 & 15.3 & 69.3 & 5.6 & 2.8 & 9.7 \\
\hline Dominican Rep. 1996 & 51.2 & & 63.7 & & 12.5 & \\
\hline Guatemala 1998-99 & 5.4 & 0.0 & 59.7 & 2.6 & 54.3 & -2.6 \\
\hline Guatemala 1995 & 5.4 & & 57.1 & & 51.7 & \\
\hline Haiti 2012 & 29.7 & 24.8 & 27.5 & 6.6 & -2.2 & 18.2 \\
\hline Haiti 1994-95 & 4.9 & & 20.9 & & 16.0 & \\
\hline
\end{tabular}




\begin{tabular}{|c|c|c|c|c|c|c|}
\hline \multirow[b]{2}{*}{ Country, Survey Year } & \multicolumn{2}{|c|}{ Lowest Quintile } & \multicolumn{2}{|c|}{ Highest Quintile } & \multirow[b]{2}{*}{ Gap } & \multirow[b]{2}{*}{ Gap Change } \\
\hline & mCPR & mCPR Rise & mCPR & mCPR Rise & & \\
\hline Honduras 2011-12 & 55.1 & 14.0 & 67.4 & 2.8 & 12.3 & 11.2 \\
\hline Honduras 2005-06 & 41.1 & & 64.6 & & 23.5 & \\
\hline Nicaragua 2001 & 50.2 & 10.0 & 71.0 & 6.8 & 20.8 & 3.2 \\
\hline Nicaragua 1998 & 40.2 & & 64.2 & & 24.0 & \\
\hline Peru 2012 & 40.5 & 30.0 & 58.1 & 9.8 & 17.6 & 20.2 \\
\hline Peru 1991-92 & 10.5 & & 48.3 & & 37.8 & \\
\hline MEAN CHANGES & & 18.2 & & 6.1 & & 12.1 \\
\hline OVERALL MEAN CHANGES & & 12.9 & & 7.8 & & 5.0 \\
\hline
\end{tabular}


APPENDIX 3. Distribution of Survey Respondents by Quintile and Urban-Rural Residence

\begin{tabular}{|c|c|c|c|c|c|c|}
\hline \multirow[b]{2}{*}{ Country, Survey Year } & \multicolumn{5}{|c|}{ Quintile } & \\
\hline & 1 & 2 & 3 & 4 & 5 & \\
\hline Indonesia, 2012 & & & & & & Total \\
\hline Urban & 6.4 & 13.6 & 21.0 & 26.4 & 32.7 & 100 \\
\hline Rural & 33.5 & 26.4 & 19.0 & 13.7 & 7.4 & 100 \\
\hline Urban & 16.0 & 34.0 & 52.5 & 65.8 & 81.5 & \\
\hline Rural & 84.0 & 66.0 & 47.5 & 34.2 & 18.5 & \\
\hline Total & 100.0 & 100.0 & 100.0 & 100.0 & 100.0 & \\
\hline Egypt, 2014 & & & & & & Total \\
\hline Urban & 3.1 & 2.8 & 4.6 & 35.8 & 53.7 & 100 \\
\hline Rural & 30.0 & 30.2 & 29.2 & 10.6 & 0.0 & 100 \\
\hline Urban & 5.6 & 5.1 & 8.3 & 66.1 & 100.0 & \\
\hline Rural & 94.4 & 94.9 & 91.7 & 33.9 & 0.0 & \\
\hline Total & 100.0 & 100.0 & 100.0 & 100.0 & 100.0 & \\
\hline Malawi, 2010 & & & & & & Total \\
\hline Urban & 2.9 & 3.4 & 7.5 & 19.9 & 66.3 & 100 \\
\hline Rural & 23.3 & 23.1 & 22.3 & 20.0 & 11.3 & 100 \\
\hline Urban & 2.3 & 2.7 & 5.9 & 15.7 & 52.4 & \\
\hline Rural & 97.7 & 97.3 & 94.1 & 84.3 & 47.6 & \\
\hline Total & 100.0 & 100.0 & 100.0 & 100.0 & 100.0 & \\
\hline
\end{tabular}

Note: The first "Urban" and "Rural" rows under each country represent the percentage of the urban and rural population, respectively, falling under each wealth quintile. The second set of "Urban" and "Rural" rows under each country represent the percentage of respondents from each wealth quintile who live in urban or rural areas, respectively. 
APPENDIX FIGURE 3. Quintile Membership by Rural and Urban Residence: Illustrative Example From Indonesia, 2012

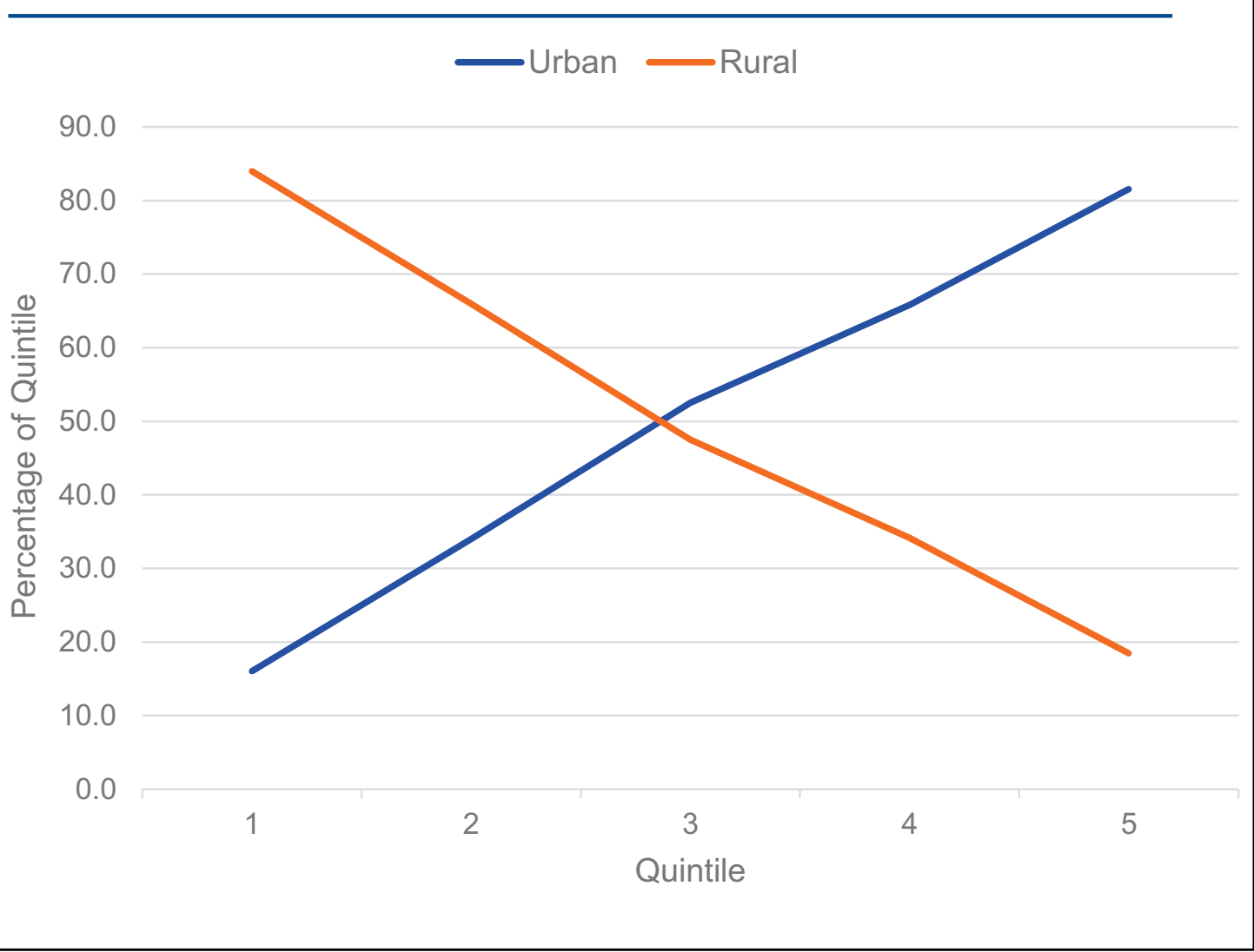

